\title{
Retraction Note: Synthetic seed technology for short term conservation of medicinal orchid Dendrobium densiflorum Lindl. Ex Wall and assessment of genetic fidelity of regenerants
}

\author{
P. Mohanty $\cdot$ J. Das
}

Published online: 4 December 2013

(C) Springer Science+Business Media Dordrecht 2013

Retraction to: Plant Growth Regul (2013) 70:297-303

DOI 10.1007/s10725-013-9801-z

This article has been retracted at the request of the Publisher due to a violation of Springer's Publishing Integrity.
The Fig. 1 of the article has been duplicated from different research papers and led to some serious scientific flaw in the article.

The online version of the original article can be found under doi:10.1007/s10725-013-9801-z.

P. Mohanty

National Research Centre for Orchids, Pakyong 737106,

Sikkim, India

J. Das $(\square)$

Plant Bioresources Division, Institute of Bioresources and

Sustainable Development (IBSD), Sikkim Centre,

Tadong 737102, Gangtok, India

e-mail: biotechjay@yahoo.co.in 